\title{
MYRINGOPLASTY, TEMPORALIS FASCIA GRAFT PLACED MEDIAL TO THE MALLEUS VERSUS LATERAL TO THE MALLEUS: A COMPARATIVE STUDY
}

\author{
A. Shobhan Babu'1, D. Ranganathswamy2, T. Shankar ${ }^{3}$, T. Vivechana ${ }^{4}$, R. Sandeep ${ }^{5}$ \\ ${ }^{1}$ Associate Professor, Department of ENT, Osmania Medical College, Hyderabad. \\ ${ }^{2}$ Assistant Professor, Department of ENT, Osmania Medical College, Hyderabad. \\ 3 Professor, Department of ENT, Osmania Medical College, Hyderabad. \\ 4Junior Resident, Department of ENT, Osmania Medical College, Hyderabad. \\ 5Junior Resident, Department of ENT, Osmania Medical College, Hyderabad.
}

\section{ABSTRACT}

\section{BACKGROUND}

Chronic Suppurative Otitis Media (CSOM) is a worldwide prevalent disease. Despite all the scientific advancement, CSOM is still considered as an important public health problem. Tympanic membrane perforation primarily results from middle ear infections, trauma and iatrogenic causes. Up to $80 \%$ of perforations heal spontaneously. The remaining required surgical repair known as Myringoplasty, an operation performed to repair or reconstruct the tympanic membrane. It was introduced by Berthold( ${ }^{3)}$ and was further developed by Wullstein and Zollner.

The aim of this study was to compare the results of underlay technique versus over-underlay technique of myringoplasty in the treatment of mucosal type of otitis media.

\section{MATERIALS AND METHODS}

This prospective study was conducted at the Department of ENT, Head and Neck Surgery, Osmania Medical College, Govt. ENT Hospital in Hyderabad, India from January 2012 to October 2015. It included 124 patients in 12-55 years of age group with a dry ear for at least 6-8 weeks with no focus of infection in nose, throat or mastoid. The data was collected from above patients and were divided into two groups with 62 in each group. Results were calculated with respect to decrease in air-bone gap whether graft was accepted or rejected and complications.

\section{RESULTS}

This study contained 124 patients, 62 in each group, overall success rate was 91.6\% that was 96.48\% in Group-A (Graft is placed medial to Tympanic membrane and Malleus) and $94.78 \%$ in Group-B (whereas graft is placed medial to the Tympanic membrane, but lateral to the handle of the malleus). Difference of AB gap in each group before and after surgery was $17.18( \pm 4.92)$ in Group-A and $16.58( \pm 4.21)$ in Group-B. No significant difference in improvement of hearing level was noticed in this study.

\section{CONCLUSION}

Over-underlay technique is more successful statistically as compared to underlay technique of myringoplasty in all age groups. Good results were noticed in underlay technique with respect to hearing improvement and graft uptake.

\section{KEYWORDS}

Conductive Deafness, Underlay-Myringoplasty, Over-Underlay Myringoplasty, Malleus.

HOW TO CITE THIS ARTICLE: Babu AS, Ranganathswamy D, Shankar T, et al. Myringoplasty, temporalis fascia graft placed medial to the malleus versus lateral to the malleus: A comparative study. J. Evolution Med. Dent. Sci. 2016;5(81):6052-6056, D0I: 10.14260/jemds/2016/1366

\section{INTRODUCTION}

Chronic Suppurative Otitis Media (CSOM) is a worldwide prevalent disease. Despite all the scientific advancement, CSOM is still considered as an important public health problem. Tympanic membrane perforation primarily results from middle ear infections, trauma and iatrogenic causes. Up to $80 \%$ of perforations heal spontaneously.(1) The remaining required surgical repair known as Myringoplasty, an operation performed to repair or reconstruct the tympanic membrane.(2)

Financial or Other, Competing Interest: None.

Submission 29-08-2016, Peer Review 25-09-2016,

Acceptance 01-10-2016, Published 08-10-2016.

Corresponding Author:

Dr. T. Shankar

Flat No. 401, Plot No. 59 \& 62

GK Rishitha Mari Gold Apts,

Hasthinapuri Colony, Sainikpuri, Secunderabad-94.

E-mail:drshankar_ms@yahoo.com

DOI: $10.14260 /$ jemds/2016/1366
It was introduced by Berthold(3) and was further developed by Wullstein(4) and Zollner.(5)

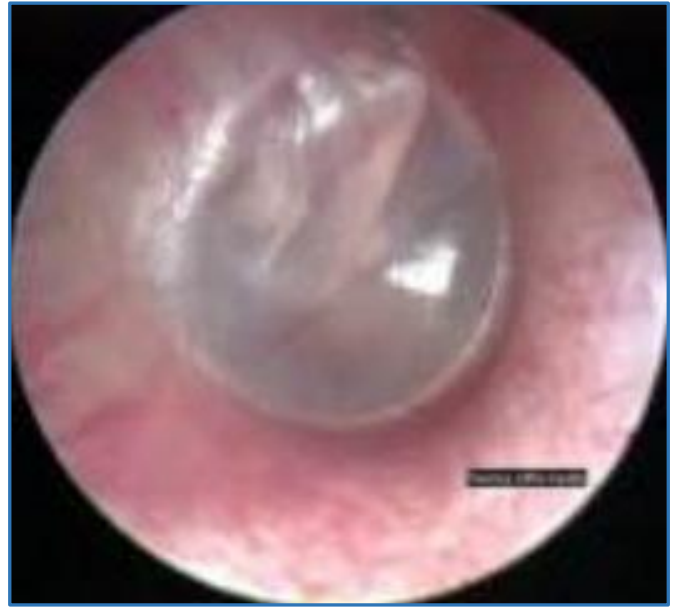

Fig. 1: Normal TM 


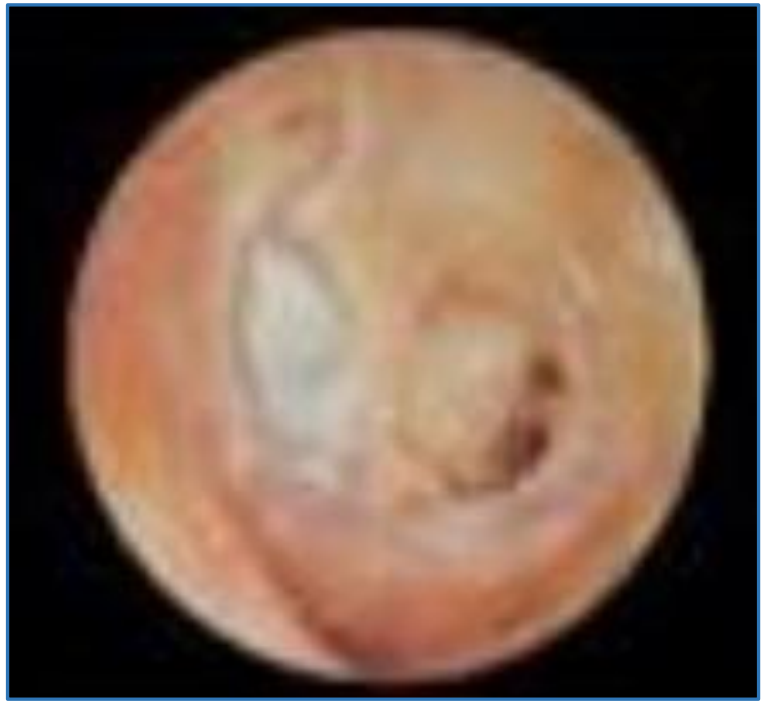

Fig. 2: Perforation in Pars Tensa

Myringoplasty is a surgical technique used to restore the integrity of tympanic membrane and to improve hearing level.(6) The two common grafting techniques used for the closure of tympanic membrane perforation are overlay and underlay.(7)

The prerequisites for myringoplasty are dry ear, good Eustachian tube function.(8) No focus of infection of nose, throat sinuses and a functioning cochlea.(9) Over the past three decades, temporalis fascia has been the most commonly used graft material in myringoplasty. The various other grafts used are fascia lata, periosteum, tragal cartilage, etc. Each of these techniques have their own advantages and disadvantages.(10,11) The underlay technique is more commonly used worldwide. In this technique the graft is placed medial to the entire tympanic membrane remnant and is also more suitable for posterior perforation. The disadvantages of this technique are decreased mesotympanic space and medial displacement of the graft. Advantages being the tympanic graft has a lower risk for lateralisation and more acceptable success rate. In overlay technique after elevation of squamous tissue, the graft is placed lateral to the annulus and fibrotic layer of the residual tympanic membrane. The overlay technique avoids this pitfall, but there is a risk of graft lateralisation, anterior blunting, stenosis of external auditory canal, delayed healing, epithelial pearls and iatrogenic cholesteatoma.

Tabb and Shea first innovated medial positioning of the graft to the malleus and residual tympanic membrane.(12,13) Kartush et al used the over-underlay technique for the tympanoplasty.(14) The perforation size is also a factor affecting the success of tympanic membrane reconstruction besides the chosen surgical technique. It has been reported that the perforation size is a prognostic factor and poorer results are obtained with large versus small perforation. In tympanic membrane reconstruction two aims should be fulfilled, the first aim is to close the perforation and second aim is to obtain a new tympanic membrane with acoustic qualities similar to that of a normal tympanic membrane.(15) Reasons for graft failure include graft displacement, autolysis, improper placement, infection and Eustachian tube dysfunction.(16)

In the present study, the tympanoplasty results of patients with CSOM who have central perforation and underwent the surgery at our hospital by the underlay or over-underlay technique were compared with respect to lateralisation of the graft, re-perforation, hearing improvement and retraction.

\section{MATERIALS AND METHODS}

This comparative study was conducted in Department of ENT, Head and Neck Surgery, Osmania Medical Government College. ENT Hospital, Koti in Hyderabad. Duration of the study was 04 years, i.e. from January 2012 to December 2015. A total of 124 cases were operated by the corresponding author by both the techniques. Among this 62 cases were operated by underlay technique and 62 cases were operated by over-underlay technique by following inclusion and exclusion criteria.

\section{Inclusion Criteria}

1. A dry tympanic membrane perforation.

Criteria for dry perforation are as follows:

- Dry ear was selected based on pathological staging of CSOM.

- Only the patients in inactive stage (Dry perforation of tympanic membrane with normal middle ear mucosa) and Quiescent stage (Perforation with a dry middle ear and mucosa, either normal or hypertrophied) of CSOM.(17)

- Perforation to be dry for at least 6-8 weeks after medical management.

2. No disease in the mastoid.

3. Good Eustachian tube function.

To check the Eustachian Tube Function, Toynbee's test was performed.

Toynbee's Test: Done in patients of perforated ear drum.

- The impedance audiometer is programmed to artificially increase or decrease the air pressure at the middle ear and then record the change of air pressure in the middle ear each time when the patient swallows.

- $\quad$ The patient is asked to swallow repeatedly and recorded graphically by impedance audiometer.

- Change of pressure during swallowing is recorded as step ladder type of graph that is normal (Graph 1).

- If some residual pressure persists even after five swallows, the tubal function is considered to be partially impaired (Graph 2).

- If positive or negative pressure built up by the impedance audiometer cannot be neutralised at all by repeated swallowing, then the ETF is considered to be grossly impaired (Graph 3).

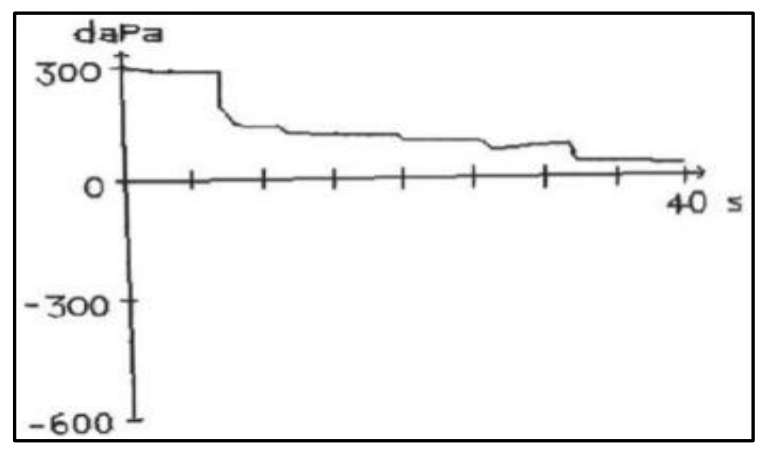

Graph 1: Normal Eustachian Tube Function 


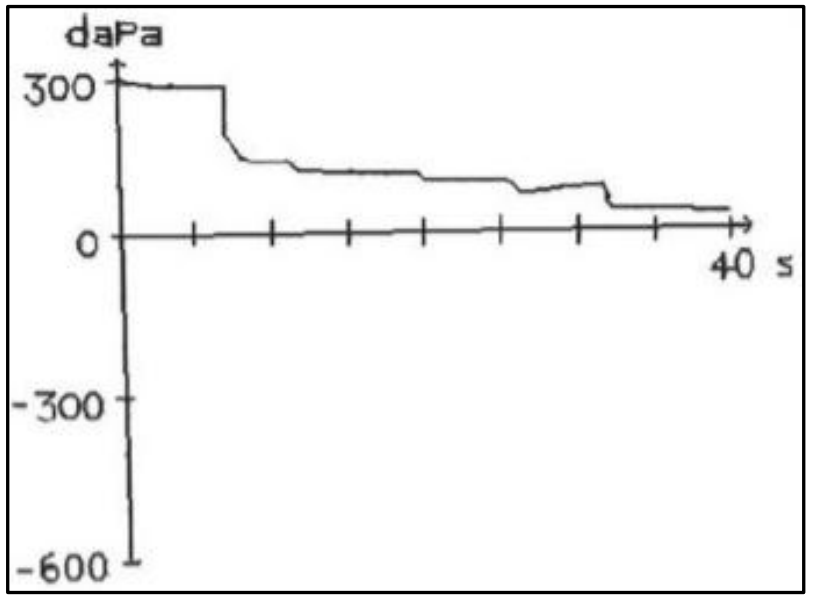

Graph 2: Partially Impaired Eustachian Tube Function

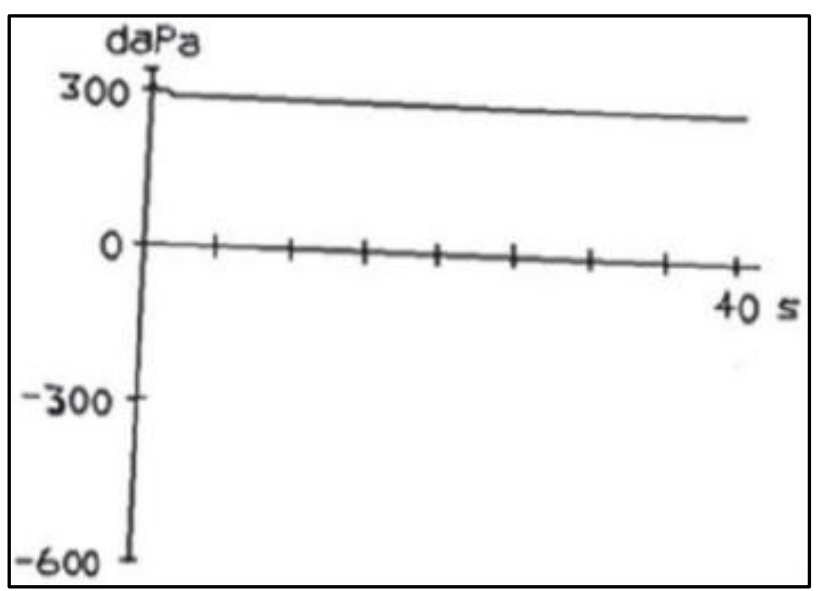

Graph 3: Totally Impaired Eustachian Tube Function

\section{A good cochlear function.}

\section{Exclusion Criteria}

1. Patients having active discharge, granulation or cholesteatoma.

2. Those with sensorineural hearing loss.

3. Active focus found in the nose, throat or sinuses.

\section{Surgical Procedure}

After clinical examination of the patients, pure tone audiogram was performed. All the surgeries were carried out under local anaesthesia. Temporalis fascia graft was harvested, post aural route was selected for both types under microscope using proper magnification.

Local anaesthetic agent $2 \%$ xylocaine with adrenaline was injected in all four quadrants of external auditory meatus. Margins of the remnant of tympanic membrane were freshened, post aural incision was given, skin of EAC incised at the bony cartilaginous junction. Tympanomeatal flap was elevated and based on superior vascular pedicle.

Spongeston (Gel foam) was placed in the middle ear cavity first by blocking the Eustachian tube and then some of it was placed in the middle ear cavity, so that the medialisation of graft is prevented. Graft was placed over the Spongeston (Gel foam) bed and tympanic meatal flap was replaced. Here in 62 cases the graft was placed medial to the handle of malleus
(Underlay Technique) and in 62 cases the graft was placed lateral to the handle of malleus of but medial to the remnant of tympanic membrane. Meatal pack is kept in EAC, wound was closed in layers, antiseptic dressing was done, meatal pack was removed on $5^{\text {th }}$ postoperative day and stitches were removed on the $7^{\text {th }}$ post-operative day.

All the patients were followed up at 02 weeks, 04 weeks and then at monthly interval for the first six months. At each visit otoscopic ear examination and Tuning fork tests were performed.

PTA was performed at the end of 6 to 8 weeks post-operatively as there is adequate time for,

- $\quad$ Proper graft uptake.

- Good healing of post aural wound.

- Absorption of the Spongeston (Gel foam) in the middle ear cavity.

We used the criteria recommended by the Japan Clinical Otology Committee for calculation of the hearing improvement (Tai, 1998).(18)

- Using the proportion of patients with a postoperative hearing within $40 \mathrm{~dB}$ as the first criterion.

- Using hearing gain exceeding $15 \mathrm{~dB}$ as the second criterion.

- Using postoperative air-bone gap within $20 \mathrm{~dB}$ as third criterion.

Data analysis was carried out to find out statistical significance of the differences and associations.

A proforma was used to collect the data. It was sorted out into gender, age, size of the perforation and location, improvement in hearing, surgical technique, post-surgical results and complications. Data interpretation, tabulation and calculations and the analytical procedures were done by a computer program SPSS for window version 11. P value was calculated to find out the degree of significance, i.e. $\mathrm{P}>0.05$.

\section{RESULTS}

A total of 124 patients in age group of $12-55$ years were equally divided into two groups A and B; 62 (50\%) in Group A were operated by over-underlay technique and 62 (50\%) in Group B cases were operated by under lay technique.

Pre-operatively in Group A and B together, 102 patients $(91.6 \%)$ had conductive hearing loss, 22 patients $(8.4 \%)$ had mixed hearing loss. Mixed hearing loss could have been due to ototoxicity due to locally produced bacterial toxins or drug induced ototoxicity. Overall success rate of surgery was 96.48\% in Group A and 94.78\% in Group B.

There were 03 perforations in Group A, 04 perforations in Group B and 1 case blunting in Group B. Fisher exact test did not show any difference between success rates of both the groups. The measurement of perforation size before surgery and the postoperative period was performed by endoscopic examination. The air bone gap in each groups before and after surgery was $17.18( \pm 4.92)$ in Group A and $16.58( \pm 4.21)$ in Group B respectively. Auditory nerve improvement was not significant in both surgical methods. No significant difference was seen between the underlay and over-underlay techniques with respect to graft uptake, re-perforation, retraction, graft lateralisation, Air-Bone Gap or Pure Tone Audiometry result. 
Air Bone Gap Comparison Before and After Surgery in Group A.

Air Bone Gap Comparison Before and After Surgery in Group B.

\begin{tabular}{|c|c|c|}
\hline $\begin{array}{c}\text { Air- } \\
\text { Bone Gap }\end{array}$ & $\begin{array}{c}\text { Number of } \\
\text { Patients } \\
\text { (Before Surgery) }\end{array}$ & $\begin{array}{c}\text { Number of } \\
\text { Patients } \\
\text { (After Surgery) }\end{array}$ \\
\hline$<=5 \mathrm{~dB} \mathrm{HL}$ & 4 & 6 \\
\hline $6-10 \mathrm{~dB}$ HL & 17 & 11 \\
\hline $\begin{array}{c}11-15 \mathrm{~dB} \\
\mathrm{HL}\end{array}$ & 30 & 42 \\
\hline$>16 \mathrm{~dB} \mathrm{HL}$ & 11 & 3 \\
\hline
\end{tabular}

\begin{tabular}{|c|c|c|}
\hline $\begin{array}{c}\text { Air- } \\
\text { Bone Gap }\end{array}$ & $\begin{array}{c}\text { Number of } \\
\text { Patients } \\
\text { (Before Surgery) }\end{array}$ & $\begin{array}{c}\text { Number of } \\
\text { Patients } \\
\text { (After Surgery) }\end{array}$ \\
\hline$<=5 \mathrm{~dB} \mathrm{HL}$ & 18 & 4 \\
\hline $6-10 \mathrm{~dB} \mathrm{HL}$ & 19 & 10 \\
\hline $11-15 \mathrm{~dB} \mathrm{HL}$ & 14 & 38 \\
\hline$>16 \mathrm{~dB} \mathrm{HL}$ & 11 & 10 \\
\hline
\end{tabular}

\section{DISCUSSION}

The aim is to repair the tympanic membrane defects to achieve anatomic and functional success and to maintain those properties over time. The absence of an adequate residual tympanic membrane in subtotal or total tympanic membrane perforations remains a challenge to ENT surgeons.(19) However, in the case of large tympanic membrane perforations, healing has a much poorer prognosis. Different techniques in myringoplasty have implemented the underlay and overlay techniques and are presently the most widely used techniques. In underlay method which is more frequently used, the graft is placed medial to malleus and residue of tympanic membrane. This procedure is performed over the overlay procedure, because of the risk of blunting coupled with the greater time and complexity needed for the latter method

The over-underlay myringoplasty is a combination of the underlay and overlay techniques. In this method, the graft is placed under the remaining drum and lateral to the malleus and has been developed to minimise the disadvantages of the other two methods. This may explain why the over-underlay technique is becoming widespread as a means of tympanic membrane repair; Karela reported on a series of 211 patients who underwent underlay myringoplasty for perforation of any size and site achieving a $91.5 \%$ success rate and a $14.67-\mathrm{dB}$ mean improvement in hearing function in $91.5 \%$ of the patients.(19) In a retrospective study in Turkey, a total of 104 patients underwent myringoplasty via underlay technique. In 46 patients the success rate with myringoplasty via underlay technique was $91.5 \%$ and with over underlay technique done in 58 patients, the success rate was $94.9 \%$. In the series reported by Kazikdas et al, the graft success rate was $95.7 \%$ using over-underlay technique.(20) In another study in Michigan Ear Institute, they chose Tympanoplasty and overunderlay myringoplasty. All their cases had successful grafts $(100 \%)$ and lateralisation of grafted drum did not occur. Average improvement in air bone gap for all patients was 5.3 dB. Fishman et al found an overall success rate of $92 \%(46 / 50)$ in a study evaluating the efficiency of total tympanic membrane reconstruction using over-underlay technique.(21)
In another study by Florino in Italy, over-underlay myringoplasty was performed in 78 patients. It was observed that graft take was obtained in $91 \%$ of cases and the audiometric results showed an average residual air-bone gap of $6.7 \mathrm{~dB} .(22)$

In our study, the graft success rate of myringoplasty performed by over-underlay technique Tympanoplasty in 62 patients operated was $95.16 \%$. Only 03 patients had graft failure. In underlay technique, 62 patients were operated with graft success rate of 94.78 and in this group 04 patients had graft failure and 02 cases presented with graft lateralisation. No statistical significance was observed between both groups with respect to re-perforation, lateralisation, retractions and success of graft uptake. On the basis of our study data, shortterm outcomes of both techniques were good and there was no significant difference between their graft uptake and audiometric results. Therefore, good tympanoplasty procedure by the surgeon carries more significance in success of surgery than the type of technique preferred during the surgery.

\begin{tabular}{|c|c|c|c|c|c|}
\hline & $\begin{array}{c}\text { Total } \\
\text { Cases }\end{array}$ & $\begin{array}{c}\text { Graft } \\
\text { Failure }\end{array}$ & Blunting & $\begin{array}{c}\text { Graft } \\
\text { Lateralisation }\end{array}$ & $\begin{array}{c}\text { No } \\
\text { Complication }\end{array}$ \\
\hline $\begin{array}{c}\text { Group } \\
\text { A }\end{array}$ & 62 & 3 & 0 & 0 & 59 \\
\hline $\begin{array}{c}\text { Group } \\
\text { B }\end{array}$ & 62 & 4 & 1 & 2 & 55 \\
\hline
\end{tabular}

The above tabular column shows a comparison of the complications that arose in Group A and B operated by overunderlay and underlay techniques respectively.

Pie Chart depicting Post-Operative Complications in Group A and Group B
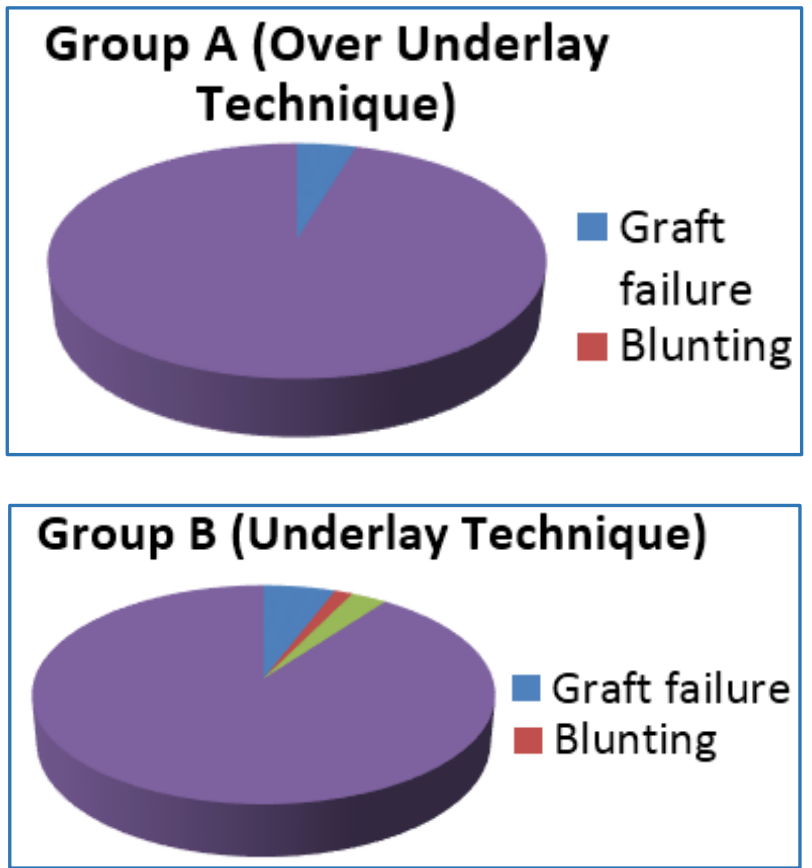

\section{CONCLUSION}

Over-underlay technique is more successful statistically as compared to underlay technique of myringoplasty in all age groups. Good results were noticed in overlay technique with respect to hearing improvement and graft uptake. In both Tympanoplasty and Myringoplasty, placing the graft medial to 
the malleus or lateral to the malleus proved to be effective in good success rate of $95.16 \%$ and $94.78 \%$. It is also worthy to mention that there are no absolute indications for any of these techniques. On the basis of our study data, short-term outcomes of both techniques were good and there was no significant difference between their graft uptake and audiometric results. Therefore, good tympanoplasty procedure by the surgeon carries more significance in success of surgery than the type of technique preferred during the surgery.

\section{REFERENCES}

1. Galdstone HB, Jackler RK, Varav K. Tympanic membrane wound healing. An overview. Otolaryngol Clin North Am 1995;28(5):913-32.

2. Frootko NJ. Reconstruction of the ear. Chapter 3. In: Kerr AG, Booth JB, eds. Scott Brown's otolaryngology: otology. $6^{\text {th }}$ edn. Oxford: Butterworths-Heinman 1997:1-25.

3. Berthold E. Ueber myringoplastik. Wier Med Bull 1878;1:1627.

4. Wullstein H. Theory and practice of tympanoplasty. Laryngoscope 1956;66(8):1076-93.

5. Zollner F. The principles of plastic surgery of the soundconducting apparatus. J Laryngol Otol 1955;69(10): 637-52.

6. Aslam MA, Aslam MJ. Comparision of over-underlay techniques of myringoplasty. Pak Armed Forces Med J 2009;59(2).

7. D'Eredita R, Marko LB. Anterior tab flab versus standard underlay myringoplasty in children. Otology \& Neurology 2009;30(6):777-81.

8. Thomasen PC, Nielsen TR, Tos M. Bilateral myringoplasty in chronic otitis media. The Laryngoscope 2007;117(5): 903-6.

9. Monfared A, Bergeron CM, Ortiz J, et al. Bivalve cartilage inlay myringoplasty: an office-based procedure for closing small to medium-sized tympanic membrane perforations. Otolaryngology Head Neck Surgery 2008;139:110-15.
10. Lee HY, Auo HJ, Kang JM. Loop overlay tympanoplasty for anterior or subtotal perforations. Auris Nasus Larynx 2010;37(2):162-6.

11. Gerlinger I, Rath G, Szanyi I, et al. Myringoplasty for anterior and subtotal perforations using KTP-532 laser. Eur Arch Otorhinolaryngol 2006;263(9):816-9.

12. Shea JJ. Vein graft closure of eardrum perforations. J Laryngol Otol 1960;74:358-62.

13. Tabb HG. Experience with transcanal and postauricular myringoplasty. Transactions of the Pacific Coast Opthalmological Society Annual Meeting 1968;52:121-5.

14. Kartush JM, Michaelides EM, Becvarovski Z, et al. Overunder tympanoplasty. Laryngoscope 2002;112(5):802-7.

15. Indorewal S. Dimensional stability of free fascia grafts: clinical application. Laryngoscope 2005;115(2):278-82.

16. Adkins WY, White B. Type I tympanoplasty: influencing factors. Laryngoscope 1984;94(7):916-8.

17. Balasubramanian T. Recent nomenclature changes and classification of CSOM. www.drtbalu.com/csom_rec.htm.

18. Yuen AP, Ho WK, Hui Y, et al. Correlation of pure tone audiogram results and hearing benefit of tympanoplasty for chronic suppurative otitis media. Ann Otol Rhino Laryngol 2000;109(4):381-4.

19. Karela M, Sandeep B, Watkins A, et al. Myringoplasty: surgical outcomes and hearing improvement: is it worth performing to improve hearing? Eur Arch Otorhinolaryngol 2008;265(9):1039-42.

20. Kazikdas KC, Onal K, Boyraz I, et al. Palisade cartilage tympanoplasty for management of subtotal perforations: a comparison with the temporalis fascia technique. Eur Arch Otorhinolaryngol 2007;264(9):985-9.

21. Fishman A, Marrinam M, Huang T, et al. Total tympanic membrane reconstruction: alloderm versus temporalis fascia. Otolaryngol Head Neck Surg 2005;132(6):906-15.

22. Fiorino F, Barbieri F. 'Over-Under' myringoplasty with umbus-anchored graft. J Laryngol Otol 2008;122(8): 854-7. 